\title{
Experimental and numerical study of angle connections assembled with European profiles
}

\section{Estudio experimental y numérico de uniones con angulares ejecutadas con perfiles europeos}

$\underline{\text { J. M. Reinosa }}^{(*)}$, A. Loureiro ${ }^{(*)}$, R. Gutiérrez ${ }^{(*)}$, M. López ${ }^{(*)}$

\section{ABSTRACT}

In this paper, four specimens with different thickness of top and seat angle with double web angle connections are experimentally tested and numerically modeled. The model has been solved by means of Abaqus $囚$ finite element package. Moment rotation curves obtained from the experiments are compared with those obtained from FE models and good agreement is observed. These results validate this numerical modeling in order to use it in future studies on angle connections.

Keywords: Finite Element Method; Semi-rigid Connections; Contact; Steel Frame Design.

\section{RESUMEN}

En este artículo se presenta el ensayo experimental y el modelo numérico de cuatro uniones de estructura metálica realizadas con casquillos angulares de diferentes espesores. El problema se ha resuelto mediante el programa comercial de elementos finitos Abaqus $囚$. Las curvas experimentales momento-rotación obtenidas concuerdan razonablemente con los resultados de los modelos propuestos, de modo que con este trabajo se ha establecido una base numérica sólida para estudios posteriores.

Palabras clave: Método de los elementos finitos; uniones semirrígidas; contacto; estructuras metálicas.

(*) University of A coruña. Ferrol (Spain).

Persona de contacto/Corresponding author: jreinosa@udc.es (J. M. Reinosa)

Cómo citar este artículo/Citation: Reinosa, J. M., Loureiro, A., Gutiérrez, R., López, M. (2014). Experimental and numerical study of angle connections assembled with European profiles. Informes de la Construcción, 66(EXTRA-1): mo11, doi: http://dx.doi.org/10.3989/ic.13.096.

Licencia / License: Salvo indicación contraria, todos los contenidos de la edición electrónica de Informes de la Construcción se distribuyen bajo una licencia de uso y distribución Creative Commons Reconocimiento no Comercial 3.o. España (cc-by-nc). 


\section{INTRODUCTION}

In conventional analysis and design procedures of steel frames, beam to column connections are assumed to be either perfectly rigid or ideally pinned. Thus, the true behaviour of joints is disregarded. Moreover, semi-rigid connections have highly nonlinear behaviour so they are seldom used by designers. On the other hand semi-rigidity introduces economic and structural benefits. In order to change this trend and to establish a rational design procedure, it is very important to determinate the moment-rotation characteristics of the semirigid connections (1).

One of the typologies of semi-rigid connections is the top and seat angle connection with double web angle. The semi-rigidity concept reduces the cost and provides structural profits for both steel and composite construction.

The general Eurocode approach is based on a mechanical model that simulates the connection by a series of different components which are represented by elastic springs. These springs are characterized by a specific stiffness and strength. The appropriate coupling of these springs in parallel and series provides the global stiffness of the connection. The procedure for calculating the connection flexural resistance by means of the component methodology can result in a complex task. This complexity is due to the need of taking into account the interaction between the various bolt rows and the existence of a large number of components involved in the analysis.

Annex $\mathrm{J}$ of Eurocode3 has emphasized the need to account for the influence of the sources of deformation due to the column (the panel zone components), which can be up to $20 \%$ of the joint deformability. But the main sources of deformation in angle connections are the angles in bending (up to $70 \%$ of the joint deformability) (2).

Since Eurocode 3 does not consider specifically this type of joint, it is substantial to improve the knowledge about angle connections in order to make easy its incorporation to European steel design (2). On the other hand, this bolted connection offers several advantages respect to welded joints, especially on the sustainable construction field (3). In this study, monotonic loading tests are conducted and modeled using European profiles for the analysis of top and seat angle connections with double web angle.

On the other hand, the Finite Element Method (FEM) has become a powerful tool for investigating the effect of all relevant parameters related to the connection behavior. Nowadays, with the evolution of computers in solving structural problems, investigation is usually related to parametric analyses on FE models to investigate the behavior of bolted connections. Considering that existing tests in literature are related to American profiles and preloaded joints (2), it is very interesting to validate a solid numerical model to deal with future parametric studies on European profiled non-preloaded connections.

\section{TEST CONFIGURATION AND CONNECTION GEOMETRIES}

\subsection{Test configuration}

The test set up consist of a pair of beams connected to a central stub column via top and seat angles bolted to the flanges
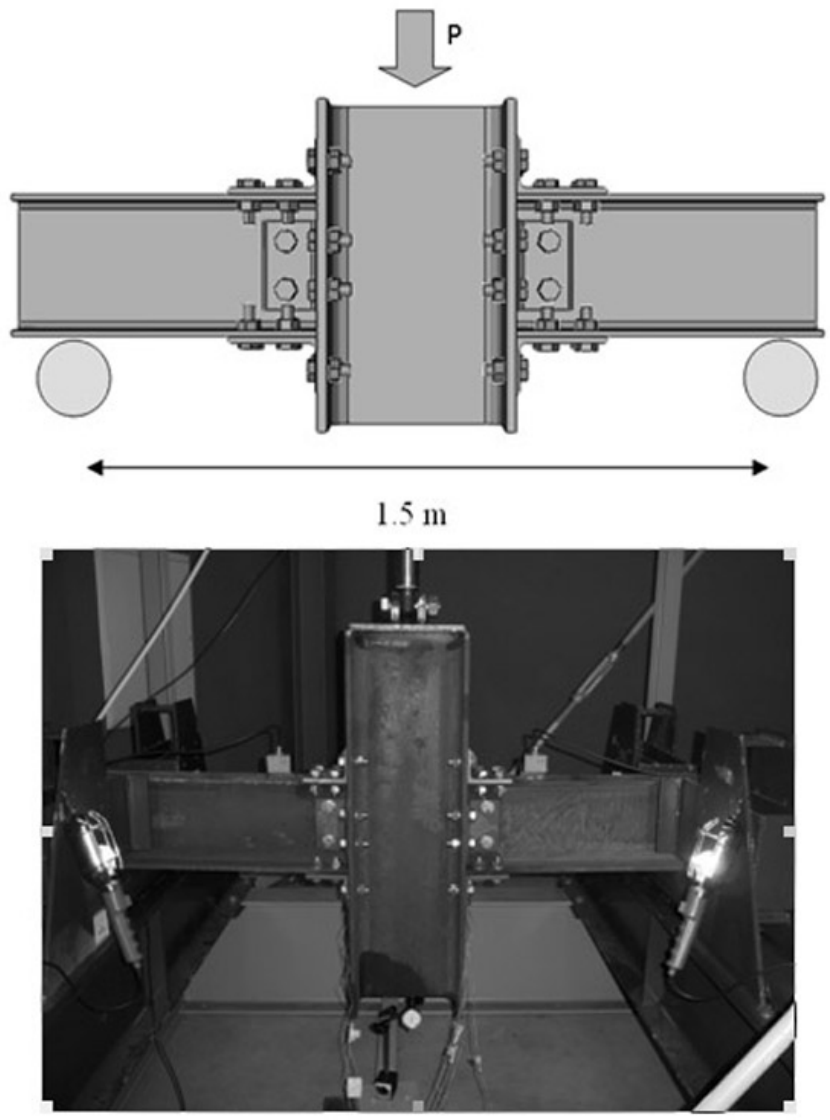

Figure 1. Test configuration.

of the beam and column and web angles bolted to the beam web and column flanges. For practical reasons, the tests have been developed on reversed configurations and the load has been applied on the column, as shown in Figure 1. Downward movement of the stub column via the actuator resulted in the connection pivoting about a point close to the top flange angle, placing the bottom flange angle in tension. The tests were carried out in the Structural Analysis Laboratory of the Higher Polytechnic University College of the University of A Coruña (Spain). The beams were supported on completely rigid rollers separated 1.5 meters length.

\subsection{Connection geometries and instrumentation}

The test set up consist of a HEA 300 column profile with IPE 240 beams attached by means of L10ox 8 web angles and top and seat angles: L120x90x12 (Test 1), L120x90x9 (Test 2), L120x90x8 (Test 3) and L120x90x10 (Test 4)

Figure 2 shows the key dimensions that define all the tests.
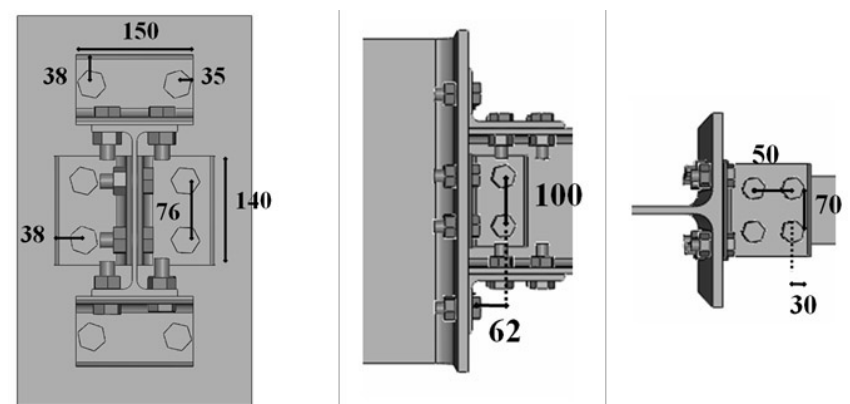

Figure 2. Key dimensions (millimetres) 
The tests were carried out by means of System 7000 data acquisition system that can be controlled using Vishay Micro-Measurements StrainSmart $®$ software. A 30 tons load cell with sensitivity $2 \mathrm{mV} / \mathrm{V}$ was placed under the actuator. Moreover, a couple of inclinometers were placed on the beams and strain gages were placed in top angles in order to capture the yielding sequence. Finally, the load was transmitted through an actuator with a load capacity of 30 tons and maximum stroke of $220 \mathrm{~mm}$.

The moment-rotation response has been computed by using the force-displacement data obtained from the tests. The force-displacement response of the connection is converted to the moment-rotation response using simple relations:

$$
M=F \lambda
$$

$$
\phi=\arctan \frac{\delta}{\lambda}
$$

Where $M$ is the moment, $\phi$ is the rotation of the connection, $F$ is the force, $\lambda$ is the length of the beam, and $\delta$ is the tip displacement of the beam.

\section{FINITE ELEMENT MODELS}

$3^{\mathrm{D}}$ finite element models of the tests have been performed. The Test 13 D FE model of top and seat angle connection with double web angles is shown in Figure 3. Symmetry about the plane of the beam web is used so half of the connection is modelled. The model was meshed by means of $\mathrm{C}_{3} \mathrm{D} 8 \mathrm{I}$ eightnode brick elements with full integration and incompatible modes and contact between all surfaces was imposed with a friction coefficient of 0.3 , by using the general contact algo-

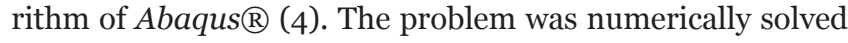
as a quasi-static process by using the Abaqus $囚$ explicit solver, because of the ease with it solves complex contact problems, as it was prove in recent works (5). The objective is to model the process in the shortest time period in which inertial forces remain insignificant. The energy balance results prove the quasi-static nature of the solution since kinetic energy remains negligible throughout the process.

Additionally, the washers were modelled as isolated elements, so that appropriate interactions between components may be developed, as they have been estimated to be relevant. Finally, the model was improved by introducing the actual length of the beam.

The experimental data describing the stress-strain top angle response is taken from coupon test for Test 1 and Test 2, and translated to true-stress-strain cuatrilineal relations to be used in the Abaqus $囚$ FE models, as it can be observed in Figure 4. For Test 3 and Test 4 coupon tests were not available, so S275 steel nominal values were used. The beam, column and web angle materials have been introduced with its S275 steel nominal values. The bolts were modelled as elastic components in order to avoid convergence problems (6).

The load was simulated by an imposed displacement on the column. To achieve the "snug tight" condition, little pretension has been applied to the bolts by means of a thermal load applied to the bolt shank. The thermal decrease is calculated

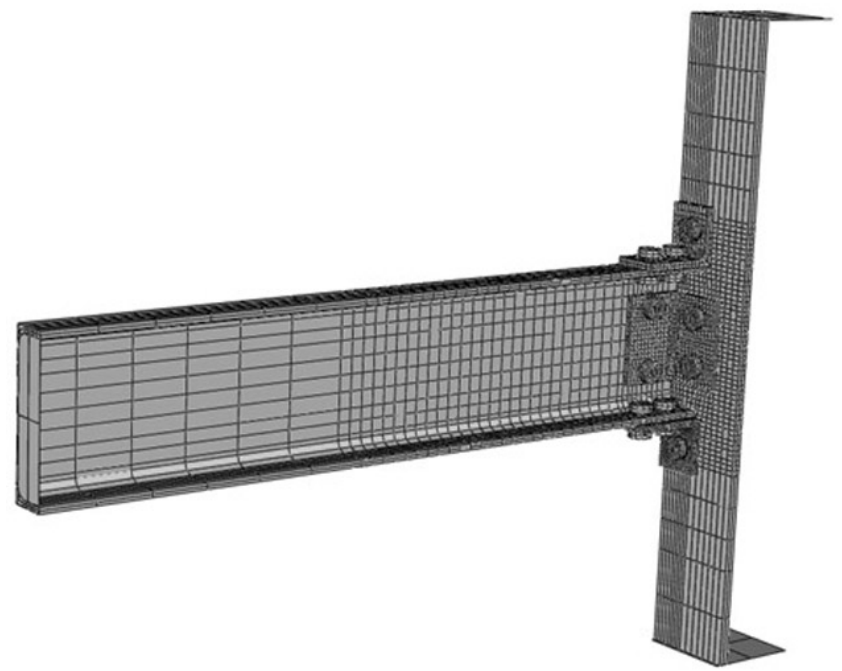

Figure 3. Finite element model of Test 1.

by means of the next equation, which disregards the head bolt deformation:

$$
\Delta T=\frac{1}{\alpha}\left[\varepsilon_{s h}-\frac{\sigma_{p}}{E}\right]
$$

Where $\sigma_{p}$ is the preloading tension in the bolt, $\alpha$ is the coefficient of thermal expansion, $E$ is the modulus of elasticity and $\varepsilon_{s h}$ is the bolt shank deformation that can be expressed as:

$$
\varepsilon_{s h}=\frac{-A_{s h} \sigma_{p}}{E A_{a}}
$$

Where $A_{a}$ is the annulus area (the effective contact area between the bolt head and the plates), and $A_{\text {sh }}$ is the bolt shank area:

$$
A_{a}=\frac{\pi\left(d_{b h}^{2}-d_{s h}^{2}\right)}{4}
$$

$$
A_{s h}=\frac{\pi d_{s h}^{2}}{4}
$$

Where $d_{b h}$ and $d_{s h}$ are the bolt head diameter and the bolt shank diameter, respectively.

Considering that the unthreaded part of the bolt is generally larger than the threaded part, the nominal value of the bolt shank diameter will be introduced in Equations 5 and 6 in accordance with the bolt geometry related to the FE model.

\section{FINITE ELEMENT RESULTS}

As it is known, two plastic hinges are developed in the tension angle. The first one is located at the toe of the fillet in the angle attached to the tension flange of the beam. The second one is located in the vicinity of the bolt line, on the leg of the angle attached to the column. Abaqus $\AA \mathrm{FE}$ package provides the plastic strain $(P E)$ that is used to represent the material's inelastic deformation. Figure 5 shows Test 2 plastic strain in 


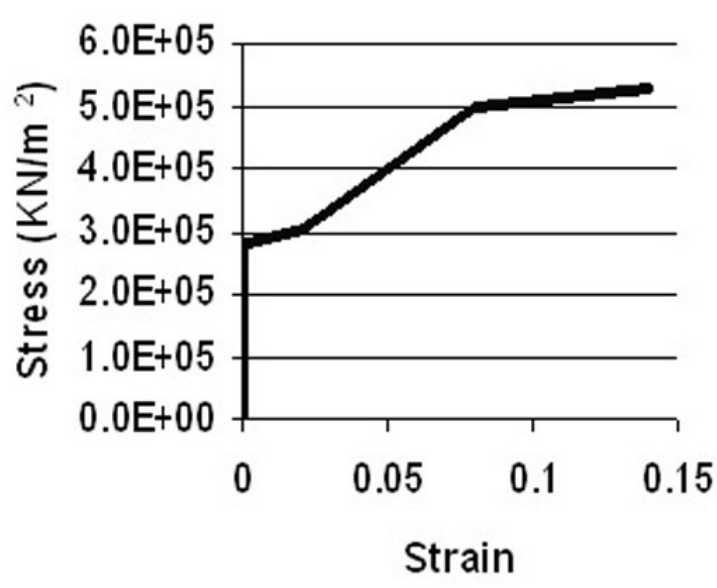

Strain

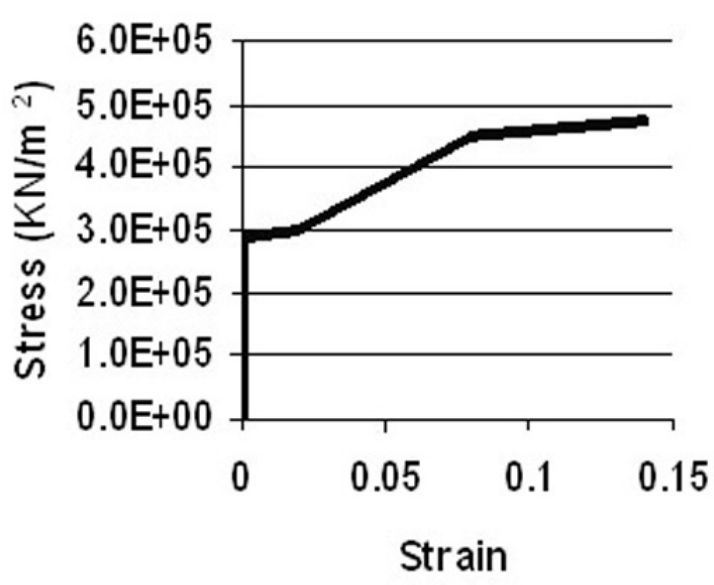

(a) the top angle, which is the most important component of this connection typology.

Figure 6 shows that the fit obtained for Test 1 is good, matching the initial stiffness of the MR curve and maintaining the yield tendency, although with a lower ultimate moment associated. On the other hand, the FE model initial stiffness is larger than the actual value of Test 2 and Test 3, as it can be observed in Figure 7 and Figure 8. Test 4 FE model fits the

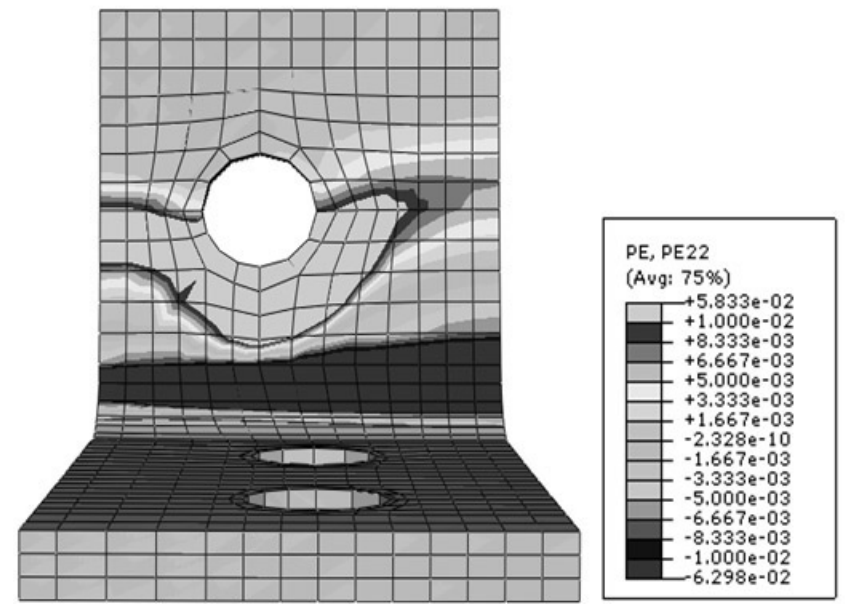

Figure 5. Finite element results of Test 2: plastic strain in the bottom angle.

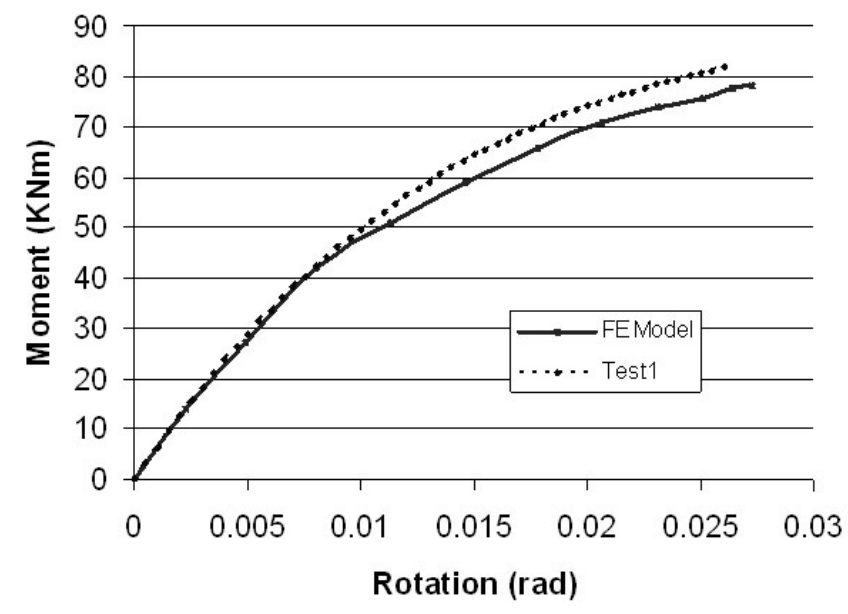

Figure 6. Moment-Rotation curves for Test 1 and the associated FE model.

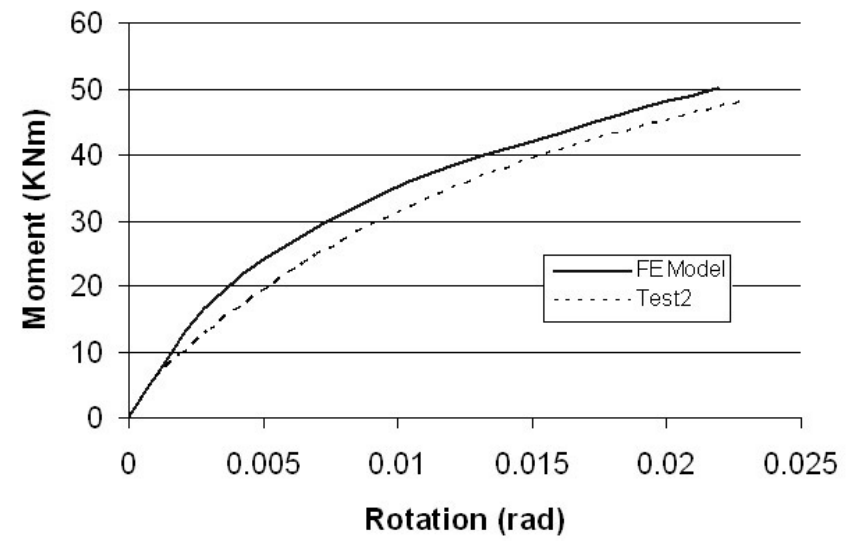

Figure 7. Moment-Rotation curves for Test 2 and the associated FE model.

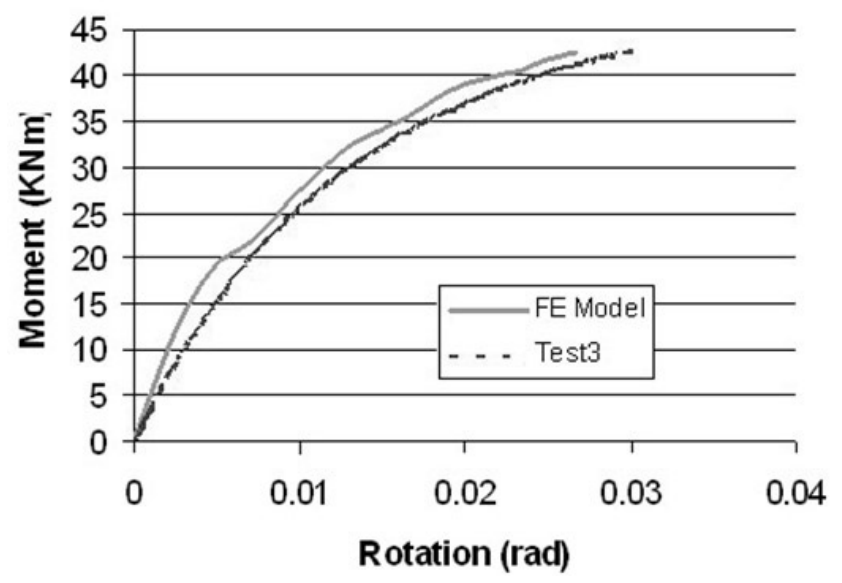

Figure 8. Moment-Rotation curves for Test 3 and the associated FE model.

initial stiffness but not the ultimate moment, which remains below the test value (Figure 9).

As it can be verified (Figure 10), the numerical models manage to reproduce the angle deformation behavior, which is the fundamental source of strain for this typology of bolted joints. In Figure 11 the final deformed configuration of Test 4 can be observed.

By comparing Test 3 (top angle thickness: $8 \mathrm{~mm}$ ) and Test 1 (top angle thickness: $12 \mathrm{~mm}$ ), both the strength and stiffness have increased by $100 \%$. 


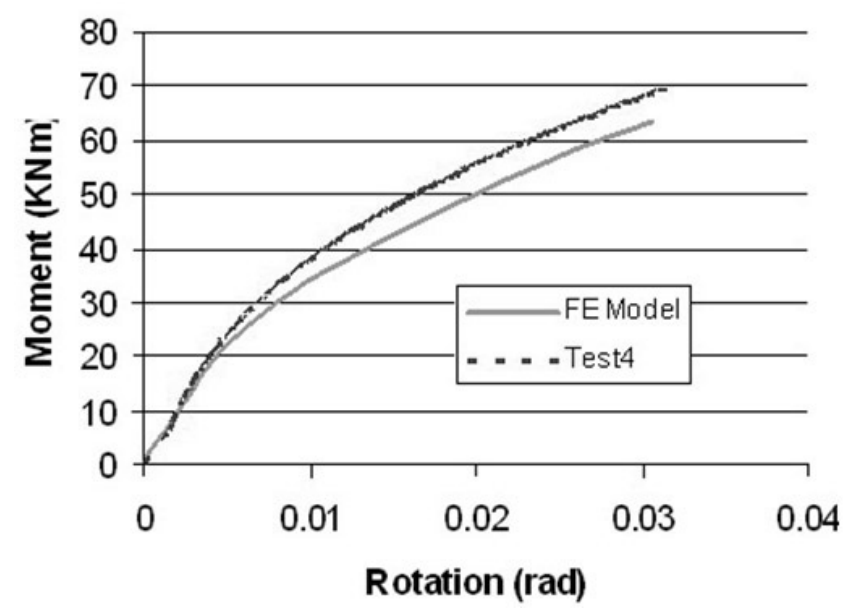

Figure 9. Moment-Rotation curves for Test 4 and the associated FE model.

These results show the possibilities of this connection in order to match with different design requirements, just varying the angle thickness (Figure 12).

\section{CONCLUSIONS}

- 3D FE models of top and seat angle connections with double web angles made up of rolled European profiles have been developed.

- In order to ease the experimental lack in literature and to obtain empirical data for comparing with numerical results, four specimens on non-preloaded European connections have been tested.

- The effectiveness of this modelling approach has been proved by comparison with experimental data, so this numerical approximation could be successfully used in future parametric studies.

- The increase in stiffness and resistance, due to angle thickness growth, has shown the possibilities of angle connections in European steel construction as an alternative to other semi-rigid typologies.

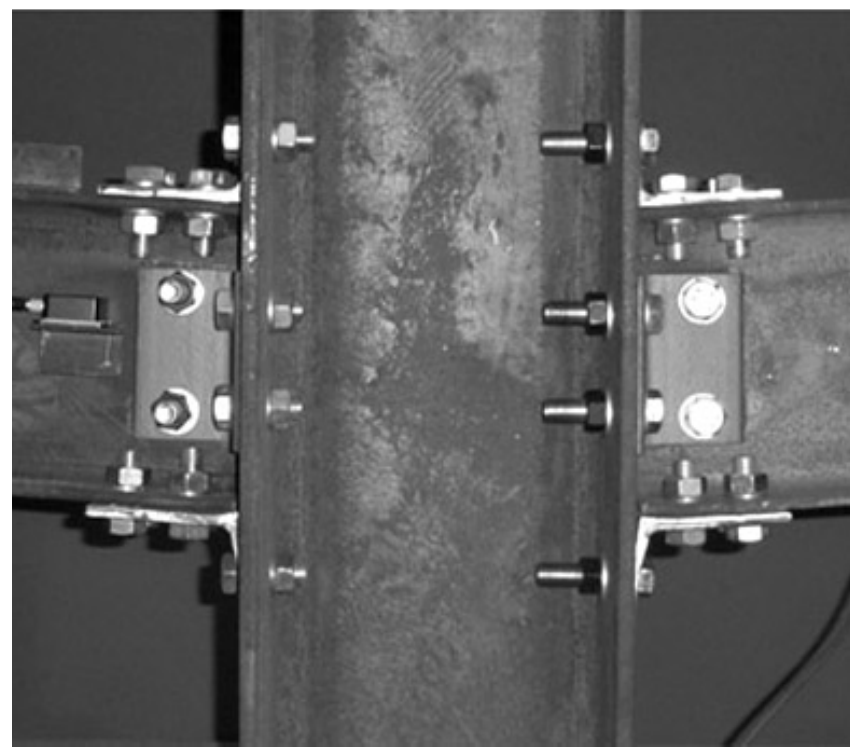

Figure 11. Deformed connection configuration for Test 4.

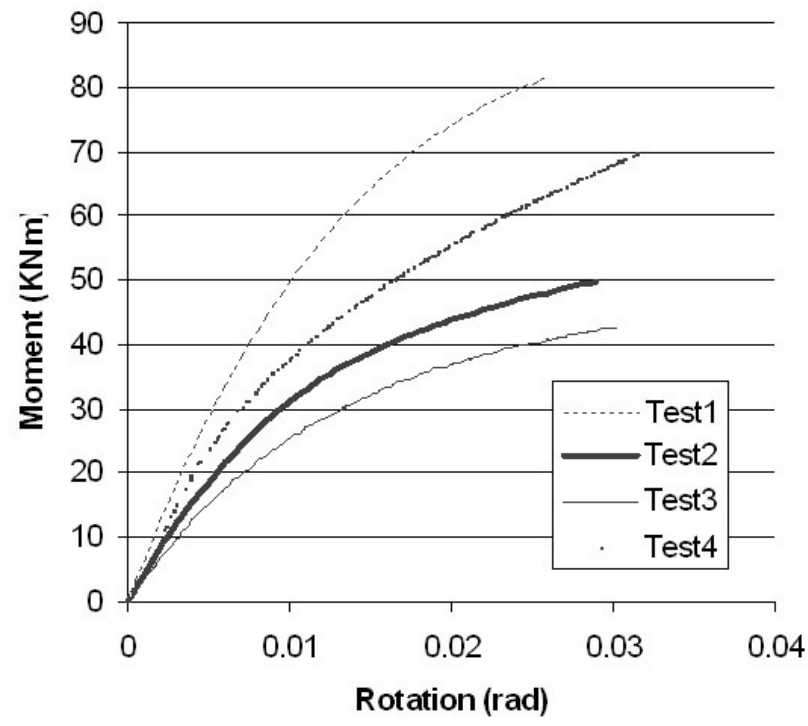

Figure 12. Comparison between Moment-Rotation experimental curves for Test 1 to Test 4 .
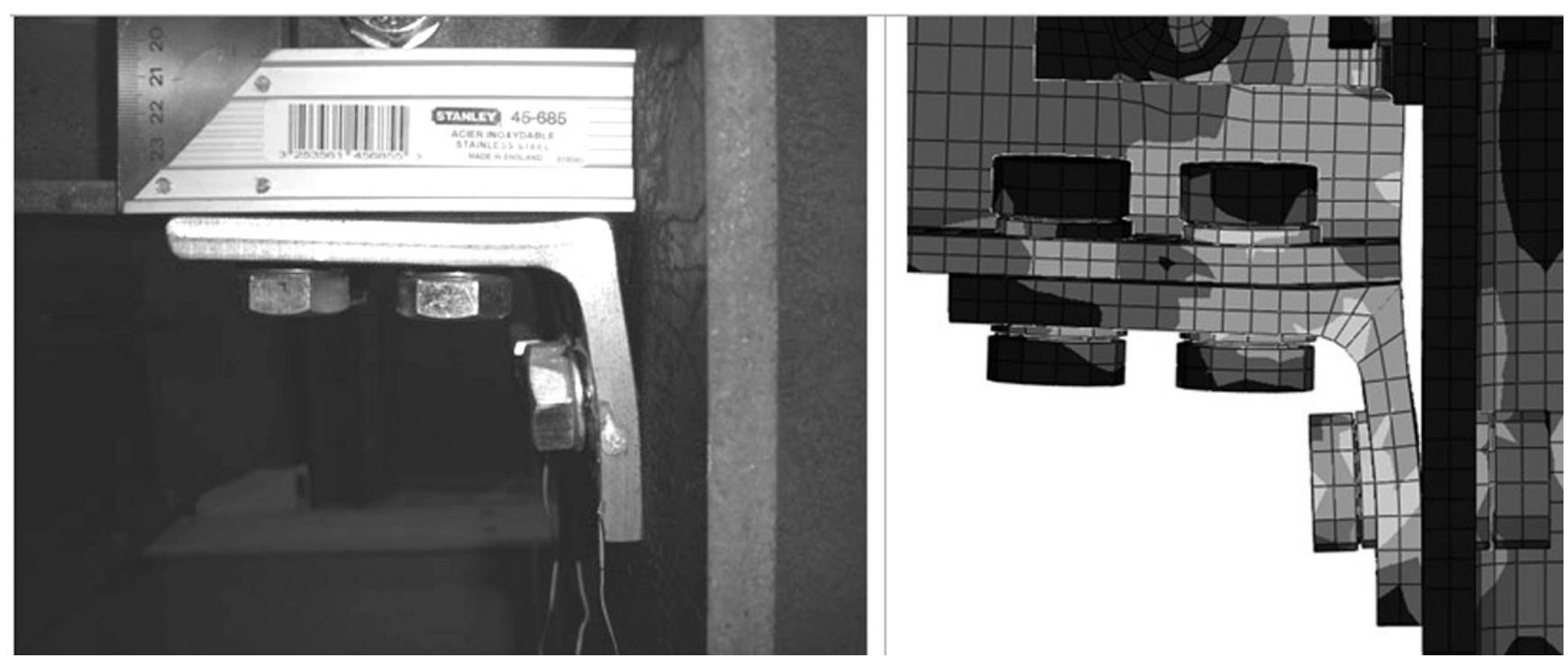

Figure 10. Comparative between test and FE model deformation behaviour in Test 1. 


\section{REFERENCES}

(1) Loureiro, A., Gutiérrez, R., Reinosa, J.M., Moreno, A. (2010). Axial stiffness prediction of non-preloaded T-stubs: An analytical frame approach. Journal of Constructional Steel Research, 66(12): 1516-1522, doi: http://dx.doi.org/10.1016/j. jcsr.2010.06.005.

(2) Loureiro, A., Reinosa, J.M., Gutiérrez, R., Moreno, A. (2011). New proposals on the calculation of the flexural resistance in angle connections. Journal of Constructional Steel Research, 67(4): 613-622, doi: http://dx.doi.org/10.1016/j. jesr.2010.11.018.

(3) Tendero, R., García-de Viedma, M. (2011). Edificación para un desarrollo sostenible: una actividad modal. Informes de la Construcción, 63(521): 75-87, doi: http://dx.doi.org/10.3989/ic.09.034.

(4) Abaqus 6.10 Analysis User's Manual. (2010). http://abaqusdoc.ucalgary.ca/books/usb/default.htm.

(5) Reinosa, J.M., Loureiro, A., Gutiérrez, R., Moreno, A. (2008). Nonlinear elastic-plastic 3d finite element modelling of Top and Seat Angle Connections with Double Web Angle. En Eurosteel 20o8: $5^{\text {th }}$ European Conference on Steel and Composite Structures (Volume A, pp. 501-506). Graz, Austria.

(6) Citipitioglu, A. M., Haj-Ali, R. M., White, D.W. (2002). Refined 3D Finite Element Modelling of Partially-Restrained Connections Including Slip. Journal of Constructional Steel Research, 58(5-8): 995-1013, doi: http://dx.doi.org/10.1016/ S0143-974X(01)00087-6. 